\title{
TINJAUAN KESELAMATAN OPERASI REAKTOR TERHADAP KINERJA MENARA PENDINGIN SETELAH 30 TAHUN BEROPERASI
}

\section{REVIEW OF REACTOR OPERATION SAFETY ON PERFORMANCE OF COOLING TOWER AFTER 30 YEARS OPERATION}

\author{
Abdul Aziz Rohman Hakim ${ }^{1}$, Sutrisno², Dicky Tri Jatmiko ${ }^{3}$ \\ 1.2.3PRSG-BATAN, Kawasan Puspiptek Gd.30, Serpong, 15310 \\ E-mail : hakim@batan.go.id
}

Diterima: 22 April 2019, diperbaiki : 9 Mei 2019, disetujui : 9 Mei 2019

\begin{abstract}
ABSTRAK
TINJAUAN KESELAMATAN OPERASI REAKTOR TERHADAP KINERJA MENARA PENDINGIN SETELAH 30 TAHUN BEROPERASI. Salah satu komponen penting dari sistem pendingin reaktor adalah menara pendingin. Menara pendingin RSG-GAS telah dioperasikan selama lebih dari 30 tahun. Telah dilakukan kajian kinerja menara pendingin pada operasi daya nominal $30 \mathrm{MW}$ ditinjau dari keselamatan operasi reaktor. Kajian dilakukan untuk mengetahui kinerja menara pendingin dalam membuang panas ke lingkungan. Parameter penilaian kinerja menara pendingin yang dipakai meliputi range, approach, efektifitas, dan temperatur pendingin masuk teras reaktor. Dari kajian data operasi tahun 1992 , diperoleh nilai range sebesar $7,2^{\circ} \mathrm{C}$, nilai approach sebesar $8,0^{\circ} \mathrm{C}$, nilai efektifitas sebesar $47,37 \%$, dan nilai temperatur pendingin masuk teras sebesar 40,0 ${ }^{\circ} \mathrm{C}$. Dari kajian data tahun 2018, diperoleh nilai range sebesar $6,7^{\circ} \mathrm{C}$, nilai approach sebesar $9,3{ }^{\circ} \mathrm{C}$, nilai efektifitas sebesar $41,84 \%$, dan nilai temperatur pendingin masuk teras sebesar $41,96{ }^{\circ} \mathrm{C}$. Nilai temperatur pendingin masuk teras data tahun 1992 masih di bawah batas pengaktifan sistem proteksi reaktor, sedangkan nilai temperatur pendingin masuk teras data tahun 2018 mendekati batas pengaktifan sistem proteksi reaktor yaitu 42 ${ }^{\circ} \mathrm{C}$. Dapat disimpulkan bahwa kinerja menara pendingin setelah 30 tahun dioperasikan sudah tidak dapat memenuhi kriteria keselamatan operasi reaktor.
\end{abstract}

Kata kunci: kinerja, menara pendingin, temperatur, keselamatan operasi.

\section{ABSTRACT}

REVIEW OF REACTOR OPERATION SAFETY ON PERFORMANCE OF COOLING TOWER AFTER 30 YEARS OPERATION. One important component of the reactor coolant system is the cooling tower. The RSG-GAS cooling tower has been operated for more than 30 years. The study of the performance of cooling towers has been carried out at a nominal power operation of $30 \mathrm{MW}$ in terms of the safety of reactor operations. The study was conducted to determine the performance of cooling towers in removing heat into the environment. Parameters for evaluating the performance of cooling towers used include the range, approach, effectiveness, efficiency and coolant temperature entering the reactor core. From a 1992 operational data study, a range value of $7,2{ }^{\circ} \mathrm{C}$ was obtained, the approach value of $8,0^{\circ} \mathrm{C}$, the effectiveness value of $47.37 \%$, and the temperature of the cooling inlet temperature was $40.0^{\circ} \mathrm{C}$. From a 2018 operational data study, the range value of $6.7^{\circ} \mathrm{C}$ was obtained, the approach value of $9.3^{\circ} \mathrm{C}$, the effectiveness value of $41.84 \%$, and the cooling inlet temperature value was $41.96^{\circ} \mathrm{C}$. The value of the cooling temperature 
entering the core in 1992 was below the reactor protection system activation limit, while the value of the cooling temperature entering the core in 2018 approached the reactor protection system activation limit. It can be concluded that the performance of cooling towers after 30 years operation cannot meet the safety criteria of reactor operations.

\section{Keywords: performance, cooling tower, temperature, operation safety}

\section{PENDAHULUAN}

Reaktor Serba Guna G.A. Siwabessy RSG-GAS) adalah salah satu reaktor riset yang ada di Indonesia. RSGGAS diresmikan pada tahun 1987. RSGGAS merupakan reaktor non daya yang digunakan untuk penelitian, pelayanan iradiasi, pendidikan dan pelatihan. RSGGAS memiliki daya nominal $30 \mathrm{MW}$ termal. Instalasi RSG-GAS dilengkapi dengan sistem-sistem yang terdiri dari beberapa komponen penting pendukung operasi reaktor. Sistem-sistem tersebut meliputi sistem ventilasi, sistem proses 1 (sistem pendingin primer), sistem penampung limbah cair, sistem proses 2 (sistem pendingin sekunder), sistem kelistrikan, proteksi radiasi, sistem monitor gempa, sistem penggerak batang kendali, dan sistem proteksi reaktor. Salah satu komponen yang merupakan bagian dari sistem pendingin sekunder reaktor adalah menara pendingin (Cooling Tower)[1].

Menara pendingin RSG-GAS telah dioperasikan selama 30 tahun. Setelah beroperasi dalam waktu yang cukup lama tersebut, telah terjadi penurunan kemampuan pemindahan panas ke lingkungan oleh menara pendingin. Hal ini menyebabkan terjadi kekurangan pendinginan ketika RSG-GAS dioperasikan pada daya nominal $30 \mathrm{MW}$. Permasalahan yang terjadi pada menara pendingin RSG-GAS antara lain: kondisi fisik menara pendingin yang telah mengalami penuaan dan tuntutan ketersediaan kinerja menara pendingin yang dapat memindahkan panas pada operasi daya nominal $30 \mathrm{MW}$. Dalam makalah ini diuraikan hasil kajian kinerja menara pendingin setelah 30 tahun dioperasikan. Kinerja menara pendingin dikaji dari data parameter temperatur pendingin yang masuk dan keluar dari teras, temperatur pendingin yang masuk dan keluar dari menara pendingin, serta kelembaban dan temperatur udara lingkungan. Data yang digunakan merupakan rekaman operasi $30 \mathrm{MW}$ teras 6 pada tanggal 25 Maret 1992 dan teras 96 pada tanggal 15 Mei 2018. Dari data tersebut kemudian dihitung parameter kinerja menara pendingin dan dilakukan komparasi terhadap nilai desain menara pendingin. Kajian yang dilakukan bertujuan untuk memberikan informasi tentang kondisi terkini dari nilai parameter kinerja menara pendingin dan perubahannya terhadap nilai desain.

\section{DASAR TEORI}

Menara pendingin (Cooling Tower) adalah sebuah perangkat yang digunakan untuk menurunkan temperatur air pendingin dengan memindahkan panas dari air pendingin ke udara lingkungan[2]. Fungsi dasar menara pendingin adalah mendinginkan air dengan cara kontak langsung antara air dengan udara. Proses pendinginan terjadi dengan cara kombinasi perpindahan panas sensibel antara air dan udara dan perpindahan panas laten yang terjadi melalui penguapan sejumlah kecil air[3]. Diagram skematik menara pendingin ditunjukkan oleh Gambar 1. 


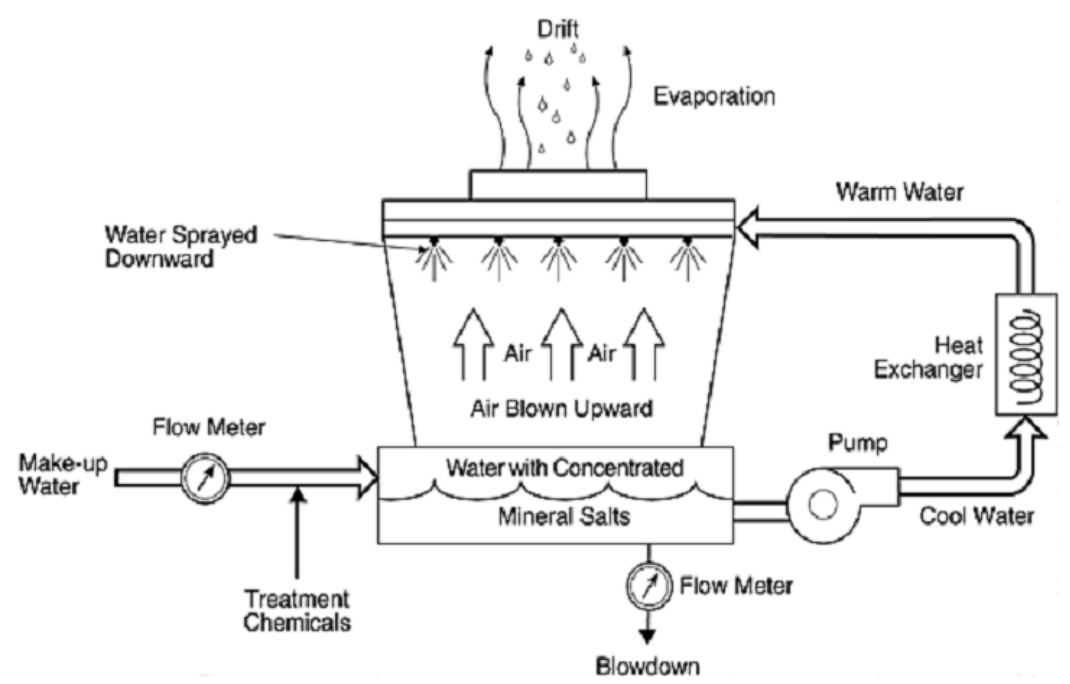

Gambar 1. Diagram Skematik Sistem Menara Pendingin[2]

Terdapat dua tipe utama menara pendingin, yaitu natural draft-atmospheric dan mechanical draft. Menara pendingin tipe natural draft menggunakan cerobong beton yang sangat besar untuk mengalirkan udara. Tinggi menara pendingin tipe natural draft adalah $155 \mathrm{~m}$ dan diameter $122 \mathrm{~m}[4]$. Karena ukurannya sangat besar, menara tipe ini umumnya digunakan pada laju aliran air lebih dari $45.000 \mathrm{~m}^{3} / \mathrm{jam}$. Tipe ini hanya digunakan pada pembangkit listrik[5]. Aliran udara dalam menara disebabkan oleh perbedaan kerapatan yang terjadi antara udara yang dipanaskan (kerapatan rendah) pada sisi dalam cerobong dan udara lingkungan yang relatif dingin (kerapatan lebih tinggi) pada sisi luar menara. Menara tipe ini juga dikenal dengan hyperbolic natural draft [6].

Menara pendingin tipe Mechanicl draft menggunakan kipas yang besar untuk mendorong atau menghisap udara melewati air yang disirkulasikan. Tinggi menara pendingin tipe mechanical draft bervariasi dari 2 meter sampai 12 meter. Komponen utamanya meliputi shell, sistem distribusi air, kolam penampung air dan kipas untuk menciptakan artifisial draft [7]. Air jatuh sepanjang permukaan pengisi (fill), sehingga menambah waktu kontak antara air dan udara. Bertambahnya waktu kontak antara air dan udara dapat meningkatkan besaran perpindahan panas. Laju pendinginan tipe mechanical draft tergantung pada diameter kipas dan kecepatan operasinya. Karena ukurannya relatif kecil, maka menara tipe ini banyak digunakan pada pendinginan sekala kecil atau industri non pembangkit listrik[5]. Menara tipe ini dapat menggunakan kipas tunggal maupun banyak untuk menyediakan aliran udara dengan jumlah volum yang diketahui melalui menara. Hal ini menjadikan menara tipe ini memiliki kinerja termal yang lebih stabil dan hanya dipengaruhi oleh sedikit variabel psychrometric dibanding menara tipe atmospheric. Keberadaan kipas juga menyediakan alat untuk mengendalikan aliran udara untuk mengkompensasi perubahan atmosfer dan kondisi beban dengan memanipulasi kapasitas kipas[6]. Menara tipe ini diklasifikasikan menjadi 
dua yaitu: force draft (kipas dipasang di sisi masuk udara lingkungan) dan induced draft (kipas dipasang di sisi keluar udara lingkungan). Berdasarkan arah aliran air dan udara, menara pendingin dapat diklasifikasikan menjadi

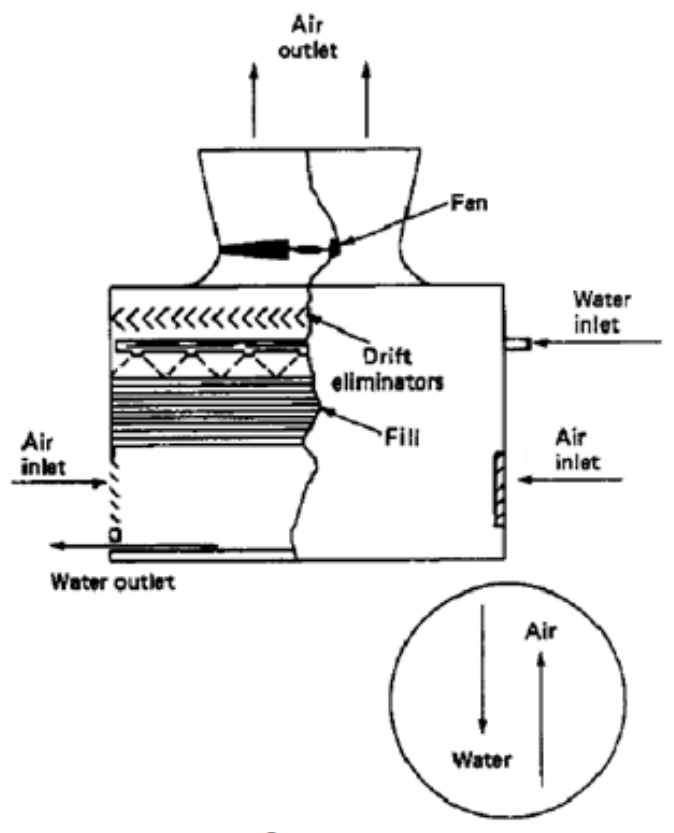

a

Gambar 2. Mechanical Draft Counterflow

Pengambilan panas oleh udara dalam menara pendingin tergantung pada temperatur dan kadar uap air di udara. Indikasi kadar air dalam udara adalah temperatur bola basah (wet bulb temperature-WBT). Idealnya, WBT adalah temperatur paling rendah dimana air dapat didinginkan. Kenyataannya, pendekatan temperatur air dingin (cold water temperatur-CWT) tidak sama dengan WBT udara karena tidak mungkin terjadi kontak antara air dan udara secara keseluruhan saat air jatuh melalui fill ke kolam penampung. Besarnya nilai pendekatan WBT tergantung pada desain menara pendingin. Faktor pentingnya adalah counterflow cooling tower (berlawanan arah) dan crossflow cooling tower (bersilangan arah). Gambar menara pendingin counterflow dan crossflow ditunjukkan pada Gambar 2.

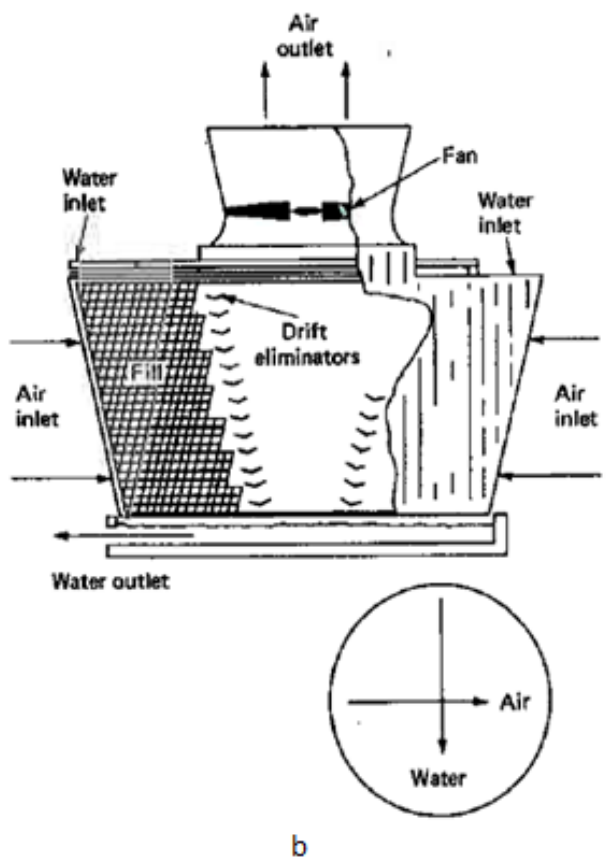

(a) and Crossflow Cooling Tower (b)[4]

lama waktu kontak udara dan air, jumlah luasan permukaan fill dan jumlah air yang menjadi tetesan[8]. Semakin kecil perbedaan antara WBT dan CWT maka kinerja menara pendingin semakin bagus.

Kinerja menara pendingin dievaluasi untuk menilai keadaan terakhir dari range, approach, dan effectiveness menara pendingin terhadap nilai desain. Skematik nilai range dan approach menara pendingin ditunjukkan oleh Gambar 3. 


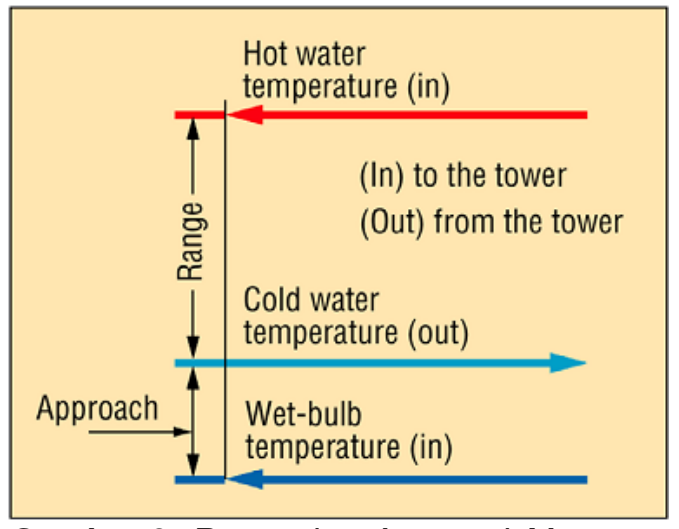

Gambar 3. Range dan Approach Menara Pendingin[5]

Berikut ini beberapa parameter terukur yang dapat digunakan untuk menentukan kinerja menara pendingin[2]:

\section{a. Range}

Range adalah selisih antara temperatur air masuk menara pendingin dan temperatur air keluar menara pendingin. Nilai range yang tinggi menunjukkan bahwa menara pendingin dapat mengurangi temperatur air secara signifikan dan kinerjanya baik. Berikut rumusnya[9]: Range $\left({ }^{\circ} \mathrm{C}\right)=\mathrm{T}_{2}\left({ }^{\circ} \mathrm{C}\right)-\mathrm{T}_{1}\left({ }^{\circ} \mathrm{C}\right)$

b. Approach

Approach adalah selisih antara temperatur air keluar dan temperatur bola basah udara luar (wet bulb temperature-WBT). Nilai approach yang lebih rendah menunjukkan kinerja menara pendingin yang lebih baik. Meskipun nilai range dan approach harus dipantau, nilai approach merupakan indikator yang lebih baik untuk menunjukkan kinerja menara pendingin. Berikut rumusnya[9]:

Approach $\left({ }^{\circ} \mathrm{C}\right)=\mathrm{T}_{1}\left({ }^{\circ} \mathrm{C}\right)-\mathrm{T}_{\mathrm{wb}}\left({ }^{\circ} \mathrm{C}\right)$

c. Effectiveness

Effectiveness adalah perbandingan antara range dan range ideal (dalam persen). Range ideal adalah selisih antara temperatur air masuk dan temperatur bola basah udara (WBT), Semakin tinggi perbandingan ini maka semakin tinggi effectiveness menara pendingin[10].

$$
\begin{aligned}
& \text { Effectiveness (\%) } \\
& =\frac{\text { Range }}{(\text { Range }+ \text { Approach })} \times 100 \%
\end{aligned}
$$

\section{METODOLOGI}

Menara RSG-GAS merupakan menara pendingin evaporatif (penguapan) tipe mechanical draft (menggunakan kipas) jenis induced draft (tarikan paksa) dengan bahan pengisi jenis film yang didesain untuk daerah tropis. Air hangat disemprotkan di bagian atas menara melalui nosel distribusi dan mengalir ke bawah sepanjang packing (sarang (1) tawon), memindahkan panas ke udara yang melewatinya melalui penguapan sebagian air yang mengalir. Kehilangan air pendingin sekunder melalui proses penguapan dan pancaran digantikan dengan melakukan penambahan air pendingin (make up water)[1]. Data desain menara pendingin ditunjukkan dalam Tabel 1.

Tabel 1. Data Desain Menara Pendingin[1]

\begin{tabular}{|l|l|}
\hline Kapasitas desain (diluar eksperimen) & $33.000 \mathrm{~kW}$ \\
\hline Jumlah unit paralel & $2 \times 50 \%$ \\
\hline Kapasitas per unit & $16.500 \mathrm{~kW}$ \\
\hline Jumlah modul paralel & 3 \\
\hline Jumlah modul total (di luar modul eksperimen) & 6 \\
\hline Kapasitas per modul & $5.500 \mathrm{~kW}$ \\
\hline
\end{tabular}




\begin{tabular}{|l|l|}
\hline Laju alir nominal per modul & $650 \mathrm{~m}^{3} / \mathrm{jam}$ \\
\hline Suhu air masuk & $39,2^{\circ} \mathrm{C}$ \\
\hline Suhu air keluar & $32^{\circ} \mathrm{C}$ \\
\hline Range & $7,2^{\circ} \mathrm{C}$ \\
\hline Suhu Approach di bagian bawah menara & $4^{\circ} \mathrm{C}$ \\
\hline Temperatur udara basah (Wet Bulb) & $28^{\circ} \mathrm{C}$ \\
\hline Temperatur udara kering (Dry Bulb) & $32^{\circ} \mathrm{C}$ \\
\hline Efektifitas (\%) (hasil perhitungan) & 64,29 \\
\hline
\end{tabular}

\section{Metode Kajian}

1. Penelusuran dan pengamatan parameter temperatur pendingin yang masuk dan keluar dari teras, temperatur pendingin yang masuk dan keluar dari menara pendingin, serta kelembaban dan temperatur udara lingkungan. Data tersebut merupakan rekaman operasi $30 \mathrm{MW}$ teras 6 pada tanggal 25 Maret 1992 dan teras 96 pada tanggal 15 Mei 2018.

2. Studi pustaka terhadap kajian menara pendingin yang pernah dilakukan

3. Perhitungan kinerja menara pendingin

4. Analisis hasil pengamatan, pengukuran dan hasil perhitungan

5. Mengambil kesimpulan

\section{PEMBAHASAN}

Pembelahan inti uranium pada bahan bakar di teras reaktor RSG-GAS menghasilkan neutron dan panas. Pada reaktor riset, panas yang dihasilkan dibuang ke lingkungan, sedangkan neutron digunakan untuk proses pembelahan berantai dan penelitian. Pembuangan panas dilakukan oleh sistem pemindah panas yang terdiri dari dua buah loop, yaitu sistem pendingin primer dan sistem pendingin sekunder. Pemindahan panas dari sistem pendingin primer ke sistem pendingin sekunder terjadi di dalam penukar panas (heat exchanger). Pada sistem pendingin sekunder, panas selanjutnya dibuang ke lingkungan melalui menara pendingin evaporatif. Menara pendingin merupakan bagian ujung dari sistem pemindah panas RSG-GAS yang membuang panas ke lingkungan. Diagram sistem pendingin RSG-GAS ditunjukkan pada Lampiran 1.

\section{Kinerja menara pendingin}

Operasi reaktor RSG-GAS

pada daya $30 \mathrm{MW}$ ditujukan untuk mengetahui kemampuan menara pendingin dalam membuang panas ke lingkungan. Operasi ini didahului dengan operasi rutin pada daya $15 \mathrm{MW}$ dengan menggunakan empat buah menara pendingin selama lima hari. Setelah operasi rutin selama lima hari, kemudian dua blower menara pendingin lainnya dihidupkan sehingga enam blower menara pendingin beroperasi. Data operasi pada daya $15 \mathrm{MW}$ dapat dilihat pada Tabel 2. Dari Tabel 2. dapat diketahui bahwa pada operasi daya yang sama, penambahan jumlah menara pendingin yang beroperasi pada sistem pendingin sekunder berpengaruh pada penurunan parameter temperatur baik pada sistem pendingin sekunder maupun pada sistem pendingin primer. Nilai selisih antara temperatur masuk dan temperatur keluar teras maupun menara pendingin tetap yaitu $4^{\circ} \mathrm{C}$. Hal ini terjadi karena besaran panas yang dipindahkan dari teras tetap $15 \mathrm{MW}$. 
Tabel 2. Data operasi pada daya $15 \mathrm{MW}$

\begin{tabular}{|l|c|c|c|c|c|c|c|}
\hline No & $\begin{array}{c}\text { Menara } \\
\text { Pendingin } \\
\text { Beroperasi }\end{array}$ & \multicolumn{3}{|c|}{ Teras Reaktor } & \multicolumn{3}{c|}{ Menara Pendingin } \\
\cline { 5 - 8 } & & $\begin{array}{c}\text { T keluar } \\
{ }^{\circ} \mathrm{C}\end{array}$ & $\begin{array}{c}\text { T masuk } \\
{ }^{\circ} \mathrm{C}\end{array}$ & $\begin{array}{c}\text { Delta T } \\
{ }^{\circ} \mathrm{C}\end{array}$ & $\begin{array}{c}\text { T keluar } \\
{ }^{\circ} \mathrm{C}\end{array}$ & $\begin{array}{c}\text { T masuk } \\
{ }^{\circ} \mathrm{C}\end{array}$ & $\begin{array}{c}\text { Delta } \\
\mathrm{T} \\
{ }^{\circ} \mathrm{C}\end{array}$ \\
\hline 1. & 4 & 42 & 38 & 4 & 36 & 40 & 4 \\
\hline 2. & 6 & 39 & 35 & 4 & 32 & 36 & 4 \\
\hline
\end{tabular}

Gambar 4. Menunjukkan hubungan antara daya dengan temperatur pendingin primer dan temperatur pendingin sekunder. Terdapat hubungan yang linier antara daya dengan temperatur pendingin primer dan temperatur pendingin sekunder. Pada rentang waktu jam 11.00 sampai jam 12.45, daya reaktor sekitar $15 \mathrm{MW}$, terlihat pada Gambar 4. bahwa parameter-parameter tersebut berada pada rentang nilai yang tetap, yaitu: temperatur pendingin primer keluar teras sekitar $39,2{ }^{\circ} \mathrm{C}$, temperatur pendingin primer masuk teras sekitar $35,2{ }^{\circ} \mathrm{C}$, temperatur pendingin sekunder keluar menara pendingin sekitar $31,8{ }^{\circ} \mathrm{C}$, temperatur pendingin sekunder masuk menara pendingin sekitar $35,02{ }^{\circ} \mathrm{C}$

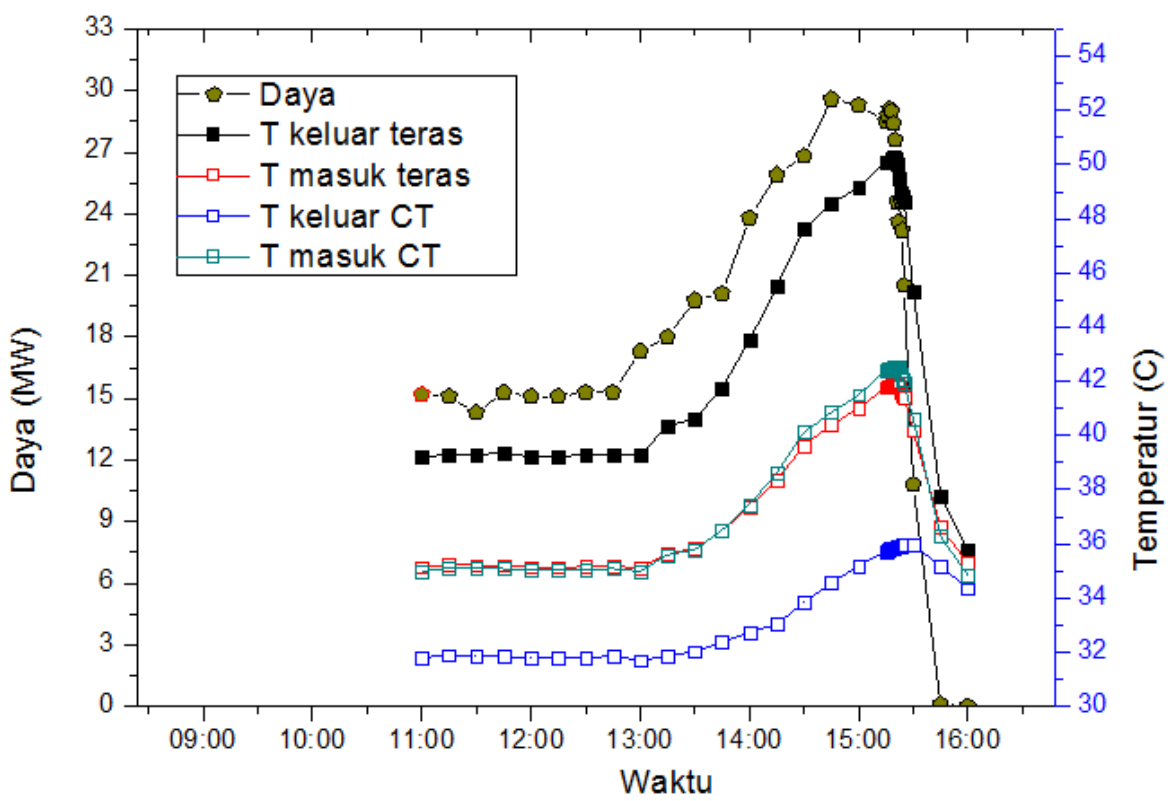

Gambar 4. Hubungan antara daya dengan temperatur pendingin

Pada jam 13.00 daya mulai dinaikkan menuju 30 MW, terlihat dari Gambar 4. bahwa ketika daya dinaikkan, temperatur pendingin primer dan sekunder tidak langsung naik seketika tetapi terdapat waktu respon kenaikan temperatur sekitar 15 menit. Demikian juga ketika daya diturunkan juga terdapat waktu respon penurunan temperatur sekitar 15 menit. Sehingga dapat dinyatakan 
bahwa antara daya dengan temperatur pendingin primer dan temperatur pendingin sekunder memiliki hubungan yang linier.

Kinerja menara pendingin pada operasi daya 30 MW ditunjukkan oleh Gambar 5. Reaktor mencapai daya operasi $30 \mathrm{MW}$ pada jam 14.45 dan dipertahankan pada daya tersebut selama 30 menit. Dalam rentang daya sekitar $30 \mathrm{MW}$, temperatur pendingin primer yang keluar dari teras naik dari $48,555{ }^{\circ} \mathrm{C}$ menjadi $50,245{ }^{\circ} \mathrm{C}$ pada menit ke 44 sebagai temperatur tertinggi. Sedangkan temperatur pendingin primer yang masuk ke teras naik dari $40,386{ }^{\circ} \mathrm{C}$ menjadi $41,962{ }^{\circ} \mathrm{C}$ pada menit ke 45 sebagai temperatur tertinggi. Temperatur pendingin sekunder yang masuk ke menara pendingin naik dari $40,845{ }^{\circ} \mathrm{C}$ menjadi $42,555{ }^{\circ} \mathrm{C}$ pada menit ke 45 sebagai temperatur tertinggi. Sedangkan temperatur pendingin sekunder yang keluar dari menara pendingin naik dari $34,555{ }^{\circ} \mathrm{C}$ menjadi $35,865{ }^{\circ} \mathrm{C}$ pada menit ke 45 . Tren kenaikan temperatur tersebut masih akan berlangsung karena kondisi tunak pada pendingin primer dan sekunder belum tercapai. Bila reaktor terus dioperasikan pada daya nominal $30 \mathrm{MW}$ dalam waktu yang lebih lama lagi untuk mencapai kondisi tunak, sedangkan kondisi tunak pada sistem pendingin primer dan sistem pendingin sekunder akan tercapai setelah 4 sampai 5 jam operasi pada daya yang konstan, maka temperatur pendingin yang masuk teras akan melebihi $42{ }^{\circ} \mathrm{C}$. Hal ini berarti bahwa temperatur pendingin primer yang masuk ke teras telah melampaui batas pengaktifan sistem proteksi reaktor sehingga memerintahkan SCRAM (safety control rod axe man) reaktor. Kondisi ini menunjukkan bahwa kinerja menara pendingin telah mengalami penurunan bila dibandingkan dengan kondisi awal komisioning. Operasi enam buah menara pendingin sudah tidak mampu memindahkan panas ke lingkungan sampai kondisi tunak sistem pendingin primer dan sistem pendingin sekunder tercapai. Variabel untuk tindakan proteksi otomatis sistem proteksi reaktor ditunjukkan pada Lampiran 4.

Parameter lingkungan saat operasi daya $30 \mathrm{MW}$ yaitu: temperatur bola basah (wet bulb temperature) adalah $26,56{ }^{\circ} \mathrm{C}$ dan temperatur bola kering (dry bulb temperature) adalah $30,44{ }^{\circ} \mathrm{C}$. Pada operasi daya nominal $30 \mathrm{MW}$, dalam keadaan belum tercapai keadaan tunak, beda temperatur antara temperatur air panas yang masuk ke menara pendingin dengan temperatur air dingin yang keluar dari menara pendingin (Range) adalah $6,69{ }^{\circ} \mathrm{C}$. Sedangkan beda temperatur antara temperatur air dingin yang keluar dari menara pendingin dengan temperatur bola basah (Approach) adalah $9,3{ }^{\circ} \mathrm{C}$. 


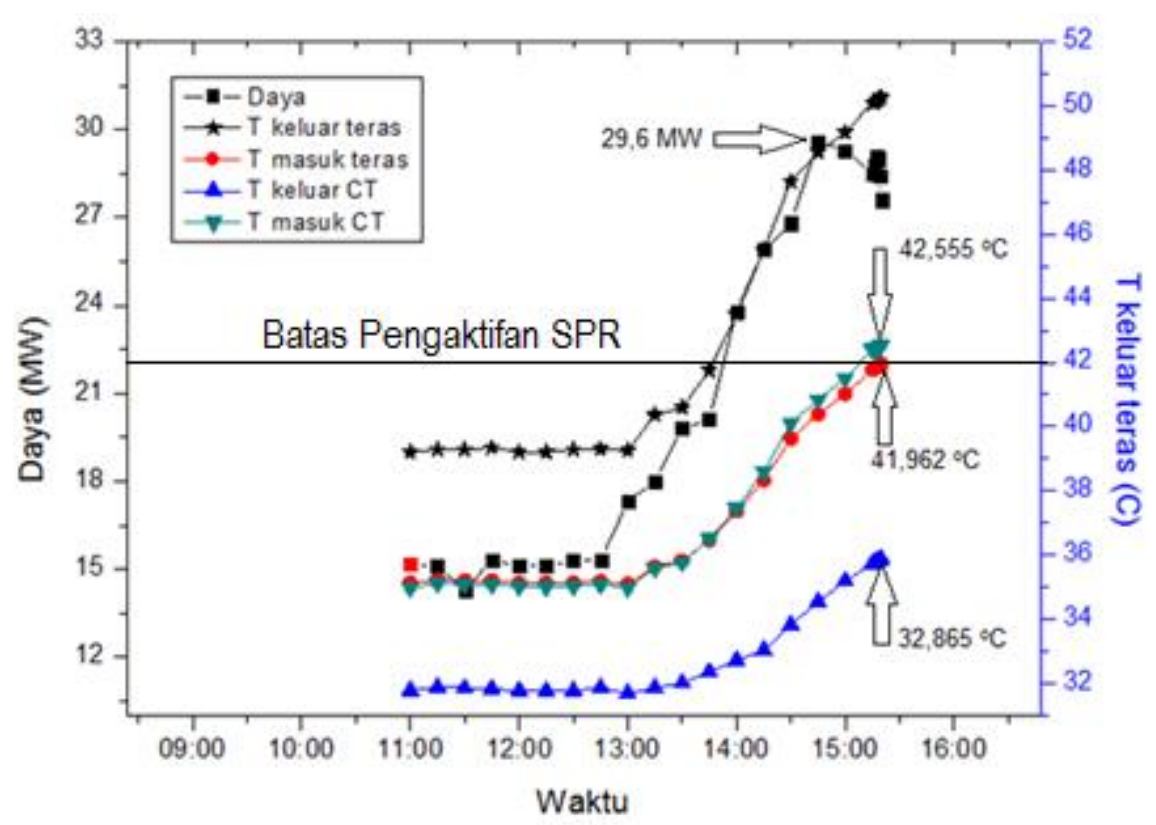

Gambar 5. Kinerja menara pendingin pada operasi daya $30 \mathrm{MW}$

Nilai range menara pendingin mendekati nilai desain yaitu $7,2{ }^{\circ} \mathrm{C}$. Hal ini terjadi karena penumpukan panas pada pendingin primer yang keluar dari teras. Temperatur pendingin primer yang keluar dari teras mencapai $50,245^{\circ} \mathrm{C}$ sehingga perpindahan panas dari pendingin primer ke pendingin sekunder menyebabkan temperatur pendingin sekunder juga tinggi dan melampaui nilai desain. Meskipun nilai range menara pendingin mendekati nilai desain, tetapi nilai approach-nya sangat besar yaitu $9,3^{\circ} \mathrm{C}$. Kinerja sebuah menara pendingin yang ideal dapat terjadi apabila temperatur pendingin yang keluar dari menara pendingin sama dengan temperatur wet bulb, atau sudah terjadi kesetimbangan panas antara air dan udara sehingga tidak terjadi perpindahan panas lagi. Keadaan ini merupakaan keadaan ideal yang tidak akan pernah tercapai. Sehingga parameter approach lebih baik untuk dijadikan indikator kinerja menara pendingin daripada nilai range. Semakin kecil nilai approach maka kinerja menara pendingin semakin baik, sebaliknya semakin besar nilai approach maka kinerja menara pendingin semakin jelek meskipun nilai range-nya besar. Kondisi ini terjadi saat operasi daya $30 \mathrm{MW}$ dengan menara pendingin akibat beban pemindahan panas yang besar pada sistem pendingin primer.

\subsection{Perhitungan kinerja menara pendingin}

Menara pendingin RSG-GAS telah beroperasi selama 30 tahun lebih. Umur operasi yang sudah cukup lama ini menyebabkan kinerja yang semakin menurun. Penilaian kinerja menara pendingin dapat dinyatakan dalam beberapa parameter lain selain range dan approach, yaitu efektifitas. Perhitungan efektifitas menara pendingin dapat dilihat pada Lampiran 2 dan Lampiran 3.

Dari data operasi reaktor pada daya 30 MW pada tahun 1992, hasil perhitungan 
menunjukkan bahwa efektifitas menara pendingin sebesar 47,37 \%[11]. Dari data operasi reaktor pada daya $30 \mathrm{MW}$ yang dilaksanakan pada 15 Mei 2018, hasil perhitungan menunjukkan bahwa efektifitas menara pendingin sebesar $41,84 \%$. Dari kedua hasil perhitungan tersebut dapat disimpulkan bahwa telah terjadi penurunan kinerja menara pendingin, ditinjau dari nilai efektifitas desain 64,29\%. Perbandingan nilai parameter kinerja menara pendingin ditunjukkan pada Tabel 3.

Tabel 3. Perbandingan Nilai Parameter Range, Approach dan Efectiveness

\begin{tabular}{|l|c|c|c|}
\hline Parameter & Desain & $\begin{array}{c}\text { Tahun } \\
1992\end{array}$ & $\begin{array}{c}\text { Ta } \\
20\end{array}$ \\
\hline Range & $7,2^{\circ} \mathrm{C}$ & $7,2^{\circ} \mathrm{C}$ & 6,7 \\
\hline Approach & $4,0^{\circ} \mathrm{C}$ & $8,0^{\circ} \mathrm{C}$ & 9,3 \\
\hline Effectiveness & $64,29 \%$ & $47,37 \%$ & 41,8 \\
\hline
\end{tabular}

\section{3. valuasi Keselamatan}

RSG-GAS didesain mampu beroperasi pada daya nominal $30 \mathrm{MW}$ termal. Untuk menjamin keselamatan operasi pada daya nominal maka ditetapkan Batasan dan Kondisi Operasi (BKO) yang telah disetujui oleh Badan Pengawas Tenaga Nuklir. Secara prinsip batasan dan kondisi operasi merupakan dasar bagi pengoperasian reaktor yang selamat, sehingga yang diuraikan dalam BKO merupakan parameter operasi dan kondisi peralatan yang sangat berkaitan dengan usaha mempertahankan dasar keselamatan. Batasan dan Kondisi Operasi Reaktor Serba Guna G.A. Siwabessy hanya berlaku selama tahap operasi reaktor saja. Pemegang Izin akan melaksanakan operasi reaktor sesuai dengan BKO pada semua mode operasi reaktor[1].

Pada kajian ini, BKO yang menjadi fokus dan terkait langsung dengan penilaian kinerja menara pendingin adalah temperatur air primer yang masuk teras.
Pada operasi daya 30 MW tahun 1992, nilai terbesar temperatur pendingin primer yang masuk teras sebesar 40,00 ${ }^{\circ} \mathrm{C}$, nilai tersebut masih di bawah batas pengaktifan sistem proteksi reaktor yaitu $42{ }^{\circ} \mathrm{C}$. Pada operasi daya $30 \mathrm{MW}$ yang dilaksanakan pada 15 Mei 2018, pada jam 15.20 WIB temperatur pendingin primer masuk teras sudah mencapai $41,96{ }^{\circ} \mathrm{C}$, dan kondisi tunak belum tercapai. Nilai temperatur pendingin masuk teras sudah mendekati batas pengaktifan sistem proteksi reaktor yaitu $42{ }^{\circ} \mathrm{C}$ dan bahkan bisa lebih besar apabila reaktor terus dioperasikan pada daya $30 \mathrm{MW}$. Tetapi, sebelum batas Tahpengaktifan sistem proteksi reaktor 201terlampaui, daya reaktor diturunkan 6,7 ifrenuju 0 MW dan reaktor di-shutdown. 9,3 Kondisi ini menunjukkan bahwa 41,84\%engambilan panas oleh sistem pendingin sekunder tidak mampu lagi menjaga temperatur air sistem pendingin primer pada kondisi tunak tetap di bawah nilai BKO dan berpotensi melampaui batas pengaktifan sistem proteksi reaktor. Sehingga dapat dinyatakan bahwa kinerja menara pendingin tidak mampu lagi memenuhi kriteria keselamatan operasi RSG-GAS. Nilai temperatur pendingin masuk teras dalam hal kesesuaian dengan BKO dapat dilihat pada Tabel 4.

Tabel 4. Temperatur Pendingin Primer

\begin{tabular}{|l|c|c|c|}
\hline Parameter & BKO & $\begin{array}{c}\text { Tahun } \\
1992\end{array}$ & $\begin{array}{c}\text { Tahun } \\
2018\end{array}$ \\
\hline Temperatur & $\begin{array}{c}42,00 \\
\text { Masuk Teras }\end{array}$ & $\begin{array}{c}{ }^{\circ} \mathrm{C} \\
40,00 \\
{ }^{\circ} \mathrm{C}\end{array}$ & $\begin{array}{c}41,96 \\
{ }^{\circ} \mathrm{C}\end{array}$ \\
\hline
\end{tabular}

\section{KESIMPULAN}

Setelah dioperasikan lebih dari 30 tahun, kinerja menara pendingin sudah mengalami penurunan. Kinerja menara pendingin tidak mampu lagi memenuhi kriteria keselamatan operasi reaktor. 
Pada operasi daya $30 \mathrm{MW}$ termal, nilai range menara pendingin sebesar $6,7^{\circ} \mathrm{C}$ mendekati nilai desain $7,2{ }^{\circ} \mathrm{C}$ tetapi parameter ini terpengaruh oleh beban pemindahan panas pada sistem pendingin primer sehingga tidak bisa dijadikan parameter kinerja menara pendingin. Nilai approach berubah dari nilai desain $4,0^{\circ} \mathrm{C}$ menjadi $9,3^{\circ} \mathrm{C}$. Nilai approach yang berubah menjadi besar menunjukkan kinerja pemindahan panas yang semakin menurun. Nilai efektifitas pemindahan panas dari menara pendingin ke lingkungan menurun dari nilai desain $64,29 \%$ menjadi $41,84 \%$.

\section{SARAN}

Kinerja pemindahan panas menara pendingin harus dikembalikan seperti semula agar dapat memenuhi kriteria keselamatan operasi pada daya nominal 30 MW termal. Perlu dilakukan penggantian fill (sarang tawon) sebagai komponen utama terjadinya perpindahan panas dan mengganti motor blower sesuai dengan spesifikasi awal agar dapat memindahkan panas seperti semula. Struktur menara pendingin dan dudukan motor blower perlu dimodifikasi menyesuaikan dengan teknologi struktur terbaru.

\section{DAFTAR LAMPIRAN}

Lampiran 1. Sistem Pendingin Reaktor Serba Guna G. A. Siwabessy

Lampiran 2. Perhitungan Kinerja Menara Pendingin pada Operasi Daya $30 \mathrm{MW}$ Tahun 1992

Lampiran3. Perhitungan Kinerja Menara Pendingin pada Operasi Daya 30 MW Sebelum Revitalisasi

Lampiran 4. Variabel Untuk Tindakan Proteksi Otomatis Sistem Proteksi Reaktor

\section{DAFTAR PUSTAKA}

1. BATAN-PRSG, Laporan Analisis Keselamatan (LAK). Safety Document, 2011. 10.1(2011): p. I2,VI-11,XVII-1.

2. Fisenko, S., A. Brin, and A. Petruchik, Evaporative cooling of water in a mechanical draft cooling tower. International Journal of Heat and Mass Transfer, 2004. 47(1): p. 165177.

3. Fisenko, S. and A. Brin, Simulation of a cross-flow cooling tower performance. International Journal of Heat and Mass Transfer, 2007. 50(15): p. 3216-3223.

4. Fisenko, S. and A. Petruchik, Toward to the control system of mechanical draft cooling tower of film type. International journal of heat and mass transfer, 2005. 48(1): p. 31-35.

5. Milosavljevic, N. and P. Heikkilä, $A$ comprehensive approach to cooling tower design. Applied Thermal Engineering, 2001. 21(9): p. 899-915.

6. Kloppers, J.C. and D.G. Kröger, $A$ critical investigation into the heat and mass transfer analysis of counterflow wet-cooling towers. International journal of heat and mass transfer, 2005. 48(3): p. 765-777.

7. Dreyer, A.A. and P. Erens, Modelling of cooling tower splash pack. International journal of heat and mass transfer, 1996. 39(1): p. 109-123.

8. Klimanek, A. and R. Białecki, Solution of heat and mass transfer in counterflow wet-cooling tower fills. International Communications in Heat and Mass Transfer, 2009. 36(6): p. 547-553.

9. Naphon, P., Study on the heat transfer characteristics of an evaporative cooling tower. International communications in heat 
and mass transfer, 2005. 32(8): p. 11.PRSG-BATAN, Lembar Operasi 1066-1074.

10.Code, E.C.B., Bureau of Energy Reaktor G. A. Siwabessy in Efficiency. Ministry of Power, Rekaman, 1992. Government of India, 2007. 


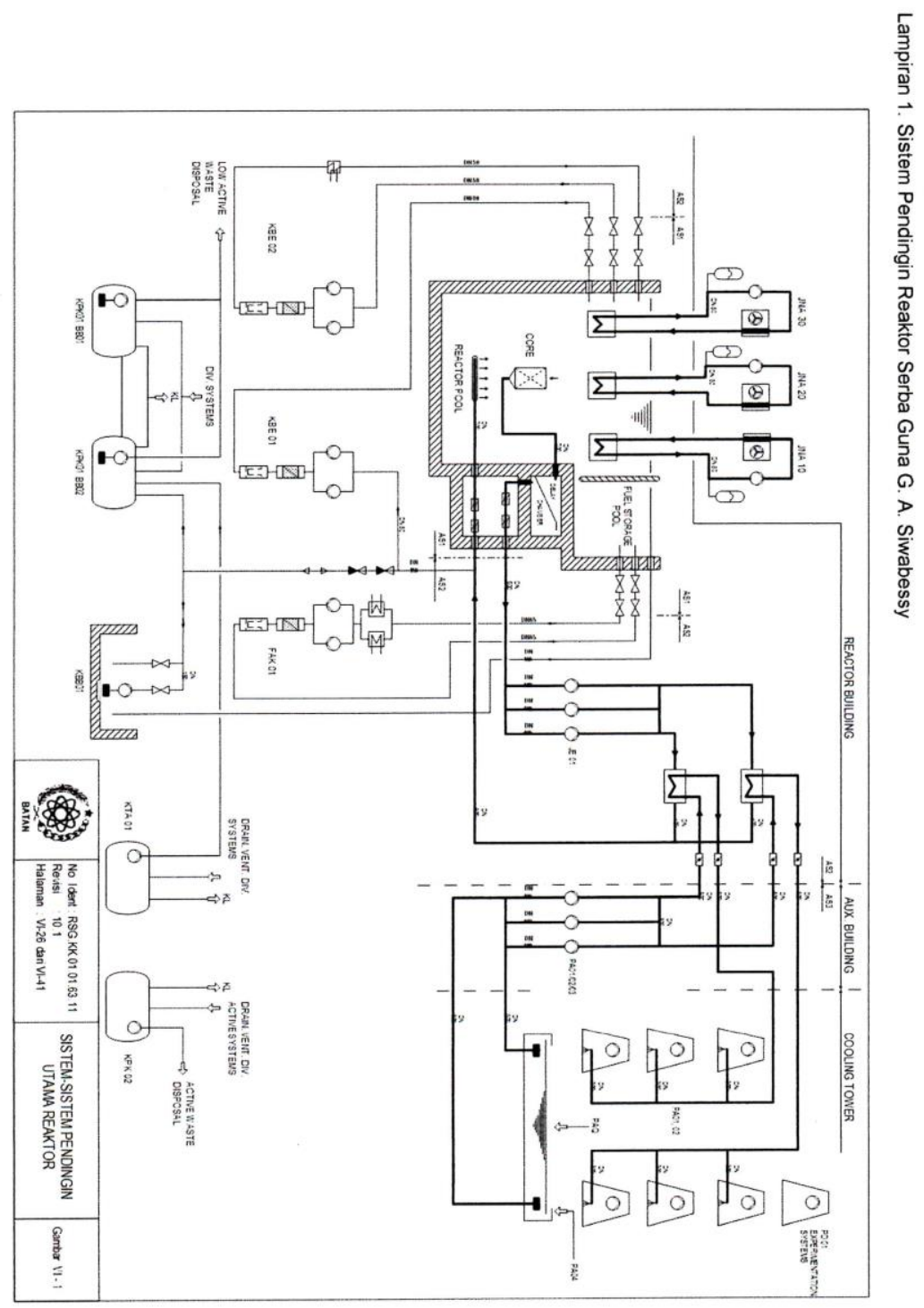


Lampiran 2. Perhitungan Kinerja Menara Pendingin pada Operasi Daya 30 MW Tahun 1992

Tabel 1. Data Pengukuran Temperatur Pendingin Masuk dan Keluar teras dan Temperatur pendingin Masuk dan Keluar Menara Pendingin

\begin{tabular}{|r|c|c|c|c|c|}
\hline \multirow{2}{*}{ Waktu } & $\begin{array}{c}\text { Daya } \\
\text { Reaktor } \\
(\mathrm{MW})\end{array}$ & \multicolumn{2}{|c|}{ Teras } & \multicolumn{2}{c|}{ Menara Pendingin } \\
\cline { 3 - 6 } & T keluar $\left({ }^{\circ} \mathrm{C}\right)$ & $\begin{array}{c}\text { T masuk } \\
\left({ }^{\circ} \mathrm{C}\right)\end{array}$ & $\begin{array}{c}\text { T air masuk } \\
\left({ }^{\circ} \mathrm{C}\right)\end{array}$ & $\begin{array}{c}\text { T air keluar } \\
\left({ }^{\circ} \mathrm{C}\right)\end{array}$ \\
\hline $0: 00$ & 30 & 45 & 39 & 43 & 34 \\
\hline $1: 00$ & 30 & 45 & 39 & 42 & 35 \\
\hline $2: 00$ & 30 & 46 & 39 & 43 & 36 \\
\hline $3: 00$ & 30 & 46 & 39 & 43 & 34 \\
\hline $4: 00$ & 30 & 46 & 39 & 42 & 35 \\
\hline $5: 00$ & 30 & 46 & 39 & 42 & 35 \\
\hline $6: 00$ & 30 & 46 & 39 & 43 & 37 \\
\hline $7: 00$ & 30 & 46 & 39 & 43 & 35 \\
\hline $8: 00$ & 30 & 46 & 39 & 43 & 36 \\
\hline $9: 00$ & 30 & 47 & 40 & 44 & 36 \\
\hline $10: 00$ & 30 & 46 & 40 & 44 & 37 \\
\hline $11: 00$ & 30 & 46 & 40 & 44 & 37 \\
\hline $12: 00$ & 30 & 46 & 40 & 44 & 37 \\
\hline $13: 00$ & 30 & 46 & 40 & 44 & 38 \\
\hline $14: 00$ & 30 & 46 & 40 & 44 & 38 \\
\hline $15: 00$ & 30 & 45 & 40 & 43 & 37 \\
\hline $16: 00$ & 30 & 39 & 40 & 44 & 37 \\
\hline $17: 00$ & 30 & 46 & 40 & 44 & 37 \\
\hline $18: 00$ & 30 & 47 & 40 & 44 & 36 \\
\hline $19: 00$ & 30 & 47 & 39,5 & 44 & 36 \\
\hline & 30 & 45,6 & 39,6 & 43,4 & 36,2 \\
\hline
\end{tabular}

Tabel 2. Data Parameter Lingkungan

\begin{tabular}{|l|l|r|l|}
\hline No & Data & Nilai & Satuan \\
\hline 1 & Temperatur Dry Bulb & 36 & ${ }^{\circ} \mathrm{C}$ \\
\hline 2 & Temperatur Wet Bulb & 28 & ${ }^{\circ} \mathrm{C}$ \\
\hline 3 & Tb1(udara masuk) & 27,3 & ${ }^{\circ} \mathrm{C}$ \\
\hline 4 & Tb2(udara keluar) & 40,5 & ${ }^{\circ} \mathrm{C}$ \\
\hline
\end{tabular}


Tabel 3. Perhitungan Efisiensi Menara Pendingin

\begin{tabular}{|c|c|c|c|}
\hline No & Data & Nilai & Satuan \\
\hline 1 & Range & 7,2 & ${ }^{\circ} \mathrm{C}$ \\
\hline 2 & Approach & 8 & ${ }^{\circ} \mathrm{C}$ \\
\hline \multirow[t]{5}{*}{3} & $\mathrm{~T}$ rata-rata air & 40 & ${ }^{\circ} \mathrm{C}$ \\
\hline & $\rho$ air pada T rata-rata & 993,6906 & $\mathrm{~kg} / \mathrm{m} 3$ \\
\hline & Laju air (Desain) & 650 & m3/jam \\
\hline & L (laju air $x \rho$ air) & 645898,89 & $\mathrm{~kg} / \mathrm{jam}$ \\
\hline & $\mathrm{L}$ & 179,42 & $\mathrm{~kg} /$ detik \\
\hline \multirow[t]{5}{*}{4} & T rata-rata udara & 33,9 & ${ }^{\circ} \mathrm{C}$ \\
\hline & $\rho$ udara pada T rata-rata & 1,155 & $\mathrm{~kg} / \mathrm{m} 3$ \\
\hline & Laju udara (Pengukuran) & 4925,6 & m3/menit \\
\hline & G (laju alir x $\rho$ udara) & 5689,068 & $\mathrm{~kg} / \mathrm{menit}$ \\
\hline & $\mathrm{G}$ & 94,82 & $\mathrm{~kg} /$ detik \\
\hline 5 & $\mathrm{~L} / \mathrm{G}$ & 1,89 & \\
\hline \multirow[t]{2}{*}{6} & \multicolumn{3}{|c|}{ Menara Pendingin dibagi menajdi 5 bagian } \\
\hline & $\mathrm{dT} / \mathrm{n}$ & 1,6 & ${ }^{\circ} \mathrm{C}$ \\
\hline \multirow[t]{3}{*}{7} & \multicolumn{3}{|c|}{ Keseimbangan energi pada bagian paling bawah } \\
\hline & \multicolumn{3}{|c|}{$\mathrm{d}(\mathrm{ha}, \mathrm{n}-\mathrm{h}$ a,n-1)=ha,1-ha0=L/G $\times 4,19 \times \mathrm{dT} / \mathrm{n}$} \\
\hline & ha, $1-$ ha $0=$ & 12,69 & $\mathrm{~kJ} / \mathrm{kg}$ \\
\hline
\end{tabular}

\begin{tabular}{|l|l|r|l|r|}
\hline \multirow{2}{*}{8} & \multicolumn{2}{|c|}{$\begin{array}{c}\text { ha,0=ha(TWB,TDB)=enthalpi udara } \\
\text { masuk ha,n=ha,n-1+L/G } \times 4,19 \times \mathrm{dT} / \mathrm{n}\end{array}$} & & ha,rata-rata \\
\hline & ha,0= & 89,19 & $\mathrm{~kJ} / \mathrm{kg}$ & \\
\hline & ha,1=ha,0+L/G $\times 4,19 \times \mathrm{dT} / \mathrm{n}$ & 101,88 & $\mathrm{~kJ} / \mathrm{kg}$ & 95,53272925 \\
\hline & ha,2=ha,1+L/G $\times 4,19 \times \mathrm{dT} / \mathrm{n}$ & 114,56 & $\mathrm{~kJ} / \mathrm{kg}$ & 108,2181877 \\
\hline & ha,3=ha,2+L/G $\times 4,19 \times \mathrm{dT} / \mathrm{n}$ & 127,25 & $\mathrm{~kJ} / \mathrm{kg}$ & 120,9036462 \\
\hline & ha,4=ha,3+L/G $\times 4,19 \times \mathrm{dT} / \mathrm{n}$ & 139,93 & $\mathrm{~kJ} / \mathrm{kg}$ & 133,5891047 \\
\hline & ha,5=ha,4+L/G $\times 4,19 \times \mathrm{dT} / \mathrm{n}$ & 152,62 & $\mathrm{~kJ} / \mathrm{kg}$ & 146,2745632 \\
\hline
\end{tabular}




\begin{tabular}{|c|c|c|c|c|c|c|}
\hline & \multicolumn{5}{|c|}{ Enthalpi Udara Jenuh (hi,rata-rata) } & \\
\hline \multicolumn{2}{|c|}{$\mathrm{T}$ air $\left({ }^{\circ} \mathrm{C}\right)$} & $\begin{array}{l}\text { T rata-rata } \\
\left({ }^{\circ} \mathrm{C}\right)\end{array}$ & In Pws & Pws & Ws & hi,rata-rata \\
\hline T0 & 36,00 & & & & & \\
\hline T1 & 37,60 & 36,80 & 8,78 & 6489,30 & 0,04256 & 146,36 \\
\hline T2 & 39,20 & 38,40 & 8,86 & 7074,27 & 0,04668 & 158,70 \\
\hline T3 & 40,80 & 40,00 & 8,95 & 7704,25 & 0,05118 & 172,03 \\
\hline T4 & 42,40 & 41,60 & 9,03 & 8382,06 & 0,05609 & 186,45 \\
\hline T5 & 44,00 & 43,20 & 9,12 & 9110,67 & 0,06145 & 202,05 \\
\hline
\end{tabular}

\begin{tabular}{|c|c|c|}
\hline \multirow[t]{2}{*}{10} & hi-ha & 1/(hi-ha) \\
\hline & $(\mathrm{kJ} / \mathrm{kg})$ & \\
\hline & 50,82 & 0,0197 \\
\hline & 50,48 & 0,0198 \\
\hline & 51,13 & 0,0196 \\
\hline & 52,86 & 0,0189 \\
\hline & 55,78 & 0,0179 \\
\hline \multicolumn{2}{|l|}{ Total } & 0,0959 \\
\hline \multicolumn{3}{|c|}{ hc.A/Cpm $=L \times 4,19 \times d T \times \Sigma 1 /($ hi-ha) } \\
\hline \multicolumn{2}{|c|}{ hc.A/Cpm (kg.d.a/kJ) } & 115,34 \\
\hline
\end{tabular}

\begin{tabular}{|l|l|l|l|}
\hline 11 & \multicolumn{3}{l|}{ Kemampuan menerima panas } \\
\hline & Q=hc.A/Cpm.(hi,n-ha,n) & Nilai & Satuan \\
\hline & Q1 & 5861,90 & $\mathrm{~kW}$ \\
\hline & Q2 & 5822,43 & $\mathrm{~kW}$ \\
\hline & Q3 & 5897,12 & $\mathrm{~kW}$ \\
\hline & Q4 & 6096,68 & $\mathrm{~kW}$ \\
\hline & Q5 & 6433,03 & $\mathrm{~kW}$ \\
\hline
\end{tabular}

\begin{tabular}{|l|l|l|l|}
\hline 12 & Efektifitas (ASHRAE) & Nilai & Satuan \\
\hline & Efektifitas=range/(range+approach) & 47,37 & $\%$ \\
\hline
\end{tabular}


Lampiran 3. Perhitungan Kinerja Menara Pendingin pada Operasi Daya $30 \mathrm{MW}$ pada Tahun 2018

Tabel 1. Data Pengukuran Temperatur Pendingin Masuk dan Keluar teras dan Temperatur pendingin Masuk dan Keluar Menara Pendingin

\begin{tabular}{|c|c|c|c|c|c|}
\hline \multirow[b]{2}{*}{ Waktu } & \multirow{2}{*}{$\begin{array}{c}\text { Daya } \\
\text { Reaktor } \\
(\mathrm{MW})\end{array}$} & \multicolumn{2}{|c|}{ Teras } & \multicolumn{2}{|c|}{ Menara Pendingin } \\
\hline & & $\begin{array}{c}\text { T Keluar } \\
\left({ }^{\circ} \mathrm{C}\right)\end{array}$ & $\begin{array}{c}\text { T Masuk } \\
\left({ }^{\circ} \mathrm{C}\right)\end{array}$ & $\begin{array}{c}\text { T Keluar } \\
\left({ }^{\circ} \mathrm{C}\right)\end{array}$ & T Masuk $\left({ }^{\circ} \mathrm{C}\right)$ \\
\hline 11.00 & 15,2 & 39,201 & 35,135 & 31,790 & 34,980 \\
\hline 11.15 & 15,1 & 39,299 & 35,232 & 31,890 & 35,115 \\
\hline 11.30 & 14,3 & 39,293 & 35,208 & 31,860 & 35,090 \\
\hline 11.45 & 15,3 & 39,353 & 35,206 & 31,840 & 35,075 \\
\hline 12.00 & 15,1 & 39,212 & 35,135 & 31,780 & 35,020 \\
\hline 12.15 & 15,1 & 39,212 & 35,135 & 31,765 & 35,010 \\
\hline 12.30 & 15,3 & 39,297 & 35,152 & 31,775 & 35,035 \\
\hline 12.45 & 15,3 & 39,308 & 35,187 & 31,870 & 35,085 \\
\hline 13.00 & 17,3 & 39,258 & 35,100 & 31,690 & 34,985 \\
\hline 13.15 & 18,0 & 40,362 & 35,638 & 31,870 & 35,600 \\
\hline 13.30 & 19,8 & 40,599 & 35,822 & 32,020 & 35,775 \\
\hline 13.45 & 20,1 & 41,753 & 36,478 & 32,365 & 36,505 \\
\hline 14.00 & 23,8 & 43,503 & 37,368 & 32,720 & 37,455 \\
\hline 14.15 & 25,9 & 45,495 & 38,336 & 33,035 & 38,605 \\
\hline 14.30 & 26,8 & 47,637 & 39,638 & 33,825 & 40,120 \\
\hline 14.45 & 29,6 & 48,555 & 40,386 & 34,550 & 40,845 \\
\hline 15.00 & 29,3 & 49,173 & 41,020 & 35,195 & 41,505 \\
\hline 15.15 & 28,5 & 50,100 & 41,773 & 35,730 & 42,410 \\
\hline 15.16 & 28,8 & 50,082 & 41,793 & 35,750 & 42,440 \\
\hline 15.17 & 29,1 & 50,119 & 41,821 & 35,805 & 42,425 \\
\hline 15.18 & 29,0 & 50,197 & 41,877 & 35,810 & 42,445 \\
\hline 15.19 & 28,4 & 50,271 & 41,897 & 35,845 & 42,505 \\
\hline 15.20 & 27,6 & 50,245 & 41,962 & 35,865 & 42,555 \\
\hline 15.21 & 24,6 & 50,043 & 41,899 & 35,890 & 42,560 \\
\hline 15.22 & 23,6 & 49,518 & 41,816 & 35,920 & 42,510 \\
\hline 15.23 & 24,7 & 48,982 & 41,567 & 35,930 & 42,290 \\
\hline 15.24 & 23,2 & 48,830 & 41,458 & 35,970 & 42,050 \\
\hline 15.25 & 20,5 & 48,652 & 41,402 & 35,970 & 41,920 \\
\hline
\end{tabular}




\begin{tabular}{|c|c|c|c|c|c|}
\hline 15.30 & 10,8 & 45,328 & 40,178 & 35,950 & 40,615 \\
\hline 15.45 & 0,1 & 37,767 & 36,615 & 35,175 & 36,275 \\
\hline 16.00 & 0,0 & 35,766 & 35,286 & 34,340 & 34,835 \\
\hline
\end{tabular}

Tabel 2. Data Parameter Lingkungan

\begin{tabular}{|c|l|r|l|}
\hline No & Data & Nilai & Satuan \\
\hline 1 & Temperatur Dry Bulb & 30,44 & ${ }^{\circ} \mathrm{C}$ \\
\hline 2 & Temperatur Wet Bulb & 26,56 & ${ }^{\circ} \mathrm{C}$ \\
\hline 3 & Tb1(udara masuk) & 30 & ${ }^{\circ} \mathrm{C}$ \\
\hline 4 & Tb2(udara keluar) & 38 & ${ }^{\circ} \mathrm{C}$ \\
\hline 6 & Air masuk CT & 42,55 & ${ }^{\circ} \mathrm{C}$ \\
\hline 7 & Air keluar CT & 35,86 & ${ }^{\circ} \mathrm{C}$ \\
\hline
\end{tabular}

Tabel 3. Perhitungan Efisiensi Menara Pendingin

\begin{tabular}{|c|c|c|c|}
\hline No & Data & Nilai & Satuan \\
\hline 1 & Range & 6,69 & ${ }^{\circ} \mathrm{C}$ \\
\hline 2 & Approach & 9,30 & ${ }^{\circ} \mathrm{C}$ \\
\hline \multirow[t]{5}{*}{3} & T rata-rata air & 39,21 & ${ }^{\circ} \mathrm{C}$ \\
\hline & $\rho$ air pada $T$ rata-rata & 992,667 & $\mathrm{~kg} / \mathrm{m} 3$ \\
\hline & Laju air (Desain) & 650 & m3/jam \\
\hline & L (laju air $\times \rho$ air) & 645233,61 & kg/jam \\
\hline & $\mathrm{L}$ & 179,23156 & $\mathrm{~kg} / \mathrm{detik}$ \\
\hline \multirow[t]{5}{*}{4} & T rata-rata udara & 34 & ${ }^{\circ} \mathrm{C}$ \\
\hline & $\rho$ udara pada T rata-rata & 1,15 & $\mathrm{~kg} / \mathrm{m} 3$ \\
\hline & Laju udara (Pengukuran) & 5880,8196 & m3/menit \\
\hline & G (laju alir $x \rho$ udara) & 6759,9327 & $\mathrm{~kg} / \mathrm{menit}$ \\
\hline & G & 98,0136 & $\mathrm{~kg} / \mathrm{detik}$ \\
\hline 5 & $L / G$ & 1,83 & \\
\hline \multirow[t]{2}{*}{6} & \multicolumn{3}{|c|}{ Menara Pendingin dibagi menajdi 5 bagian } \\
\hline & $\mathrm{dT} / \mathrm{n}$ & 1,338 & ${ }^{\circ} \mathrm{C}$ \\
\hline \multirow[t]{3}{*}{7} & \multicolumn{3}{|c|}{ Keseimbangan energi pada bagian paling bawah } \\
\hline & \multicolumn{3}{|c|}{$\mathrm{d}(\mathrm{ha}, \mathrm{n}-\mathrm{h}$ a,n-1) $=\mathrm{ha}, 1-\mathrm{ha} 0=\mathrm{L} / \mathrm{G} \times 4,19 \times \mathrm{dT} / \mathrm{n}$} \\
\hline & ha, $1-$ ha0 $=$ & 10,25 & $\mathrm{~kJ} / \mathrm{kg}$ \\
\hline
\end{tabular}




\begin{tabular}{|c|c|c|c|c|}
\hline \multirow[t]{7}{*}{8} & \multicolumn{2}{|c|}{$\begin{array}{c}\text { ha, } 0=\text { ha }(T W B, T D B)=\text { enthalpi udara masuk } \\
\text { ha, } n=\text { ha, } n-1+L / G \times 4,19 \times \mathrm{dT} / \mathrm{n}\end{array}$} & \multirow{2}{*}{$\begin{array}{l}\text { Satuan } \\
\mathrm{kJ} / \mathrm{kg}\end{array}$} & \multirow[t]{2}{*}{$\begin{array}{l}\text { ha,rata- } \\
\text { rata }\end{array}$} \\
\hline & ha, $0=$ & 82,75 & & \\
\hline & ha, $1=h a, 0+L / G \times 4,19 \times d T / n$ & 93,00 & $\mathrm{~kJ} / \mathrm{kg}$ & 87,88 \\
\hline & ha, $2=h a, 1+L / G \times 4,19 \times d T / n$ & 103,25 & $\mathrm{~kJ} / \mathrm{kg}$ & 98,13 \\
\hline & ha,3=ha,2+L/G $\times 4,19 \times \mathrm{dT} / \mathrm{n}$ & 113,51 & $\mathrm{~kJ} / \mathrm{kg}$ & 108,38 \\
\hline & ha, $4=$ ha, $3+\mathrm{L} / \mathrm{G} \times 4,19 \times \mathrm{dT} / \mathrm{n}$ & 123,76 & $\mathrm{~kJ} / \mathrm{kg}$ & 118,63 \\
\hline & ha, $5=$ ha, $4+\mathrm{L} / \mathrm{G} \times 4,19 \times \mathrm{dT} / \mathrm{n}$ & 134,01 & $\mathrm{~kJ} / \mathrm{kg}$ & 128,88 \\
\hline
\end{tabular}

\begin{tabular}{|l|r|r|r|r|r|r|}
\hline \multicolumn{2}{|c|}{9} & \multicolumn{6}{|c|}{ Enthalpi Udara Jenuh (hi,rata-rata) } \\
\hline \multicolumn{2}{|c|}{ T air $\left({ }^{\circ} \mathrm{C}\right)$} & $\begin{array}{r}\text { T rata-rata } \\
\left({ }^{\circ} \mathrm{C}\right)\end{array}$ & \multicolumn{1}{c|}{ In Pws } & \multicolumn{1}{c|}{ Pws } & Ws & hi,rata-rata \\
\hline T0 & 35,86 & & & & & \\
\hline T1 & 37,20 & 36,53 & 10,25 & 6349,08 & 0,04158 & 143,54 \\
\hline T2 & 38,54 & 37,87 & 10,25 & 6826,20 & 0,04493 & 153,60 \\
\hline T3 & 39,87 & 39,21 & 10,25 & 7334,00 & 0,04853 & 164,33 \\
\hline T4 & 41,21 & 40,54 & 10,25 & 7874,10 & 0,05241 & 175,78 \\
\hline T5 & 42,55 & 41,88 & 10,25 & 8448,17 & 0,05658 & 188,00 \\
\hline
\end{tabular}

\begin{tabular}{|l|r|r|}
\hline 10 & \multicolumn{1}{|l|}{ hi-ha } & \multicolumn{1}{|l|}{$1 /$ hi-ha $)$} \\
\hline & $(\mathrm{kJ} / \mathrm{kg})$ & \\
\hline & 55,67 & 0,0180 \\
\hline & 55,48 & 0,0180 \\
\hline & 55,95 & 0,0179 \\
\hline & 57,15 & 0,0175 \\
\hline & 59,12 & 0,0169 \\
\hline Total & 0,0883 \\
\hline \multicolumn{2}{|r|}{ hc.A/Cpm = L x 4,19 $\times$ dT x $\Sigma 1 /($ hi-ha $)$} \\
\hline \multicolumn{2}{|c|}{ hc.A/Cpm (kg.d.a/kJ) } & 88,698 \\
\hline
\end{tabular}




\begin{tabular}{|l|l|l|l|}
\hline 11 & \multicolumn{3}{|l|}{ Kemampuan menerima panas } \\
\hline & Q=hc.A/Cpm.(hi,n-ha,n) & Nilai & Satuan \\
\hline & Q1 & 4937,510 & $\mathrm{~kW}$ \\
\hline Q2 & 4920,699 & $\mathrm{~kW}$ \\
\hline Q3 & 4963,048 & $\mathrm{~kW}$ \\
\hline Q4 & 5069,136 & $\mathrm{~kW}$ \\
\hline & Q5 & 5243,956 & $\mathrm{~kW}$ \\
\hline
\end{tabular}

\begin{tabular}{|l|l|l|l|}
\hline 12 & Efektifitas (ASHRAE) & Nilai & Satuan \\
\hline & Efektifitas=range/(range+approach) & 41,84 & $\%$ \\
\hline
\end{tabular}




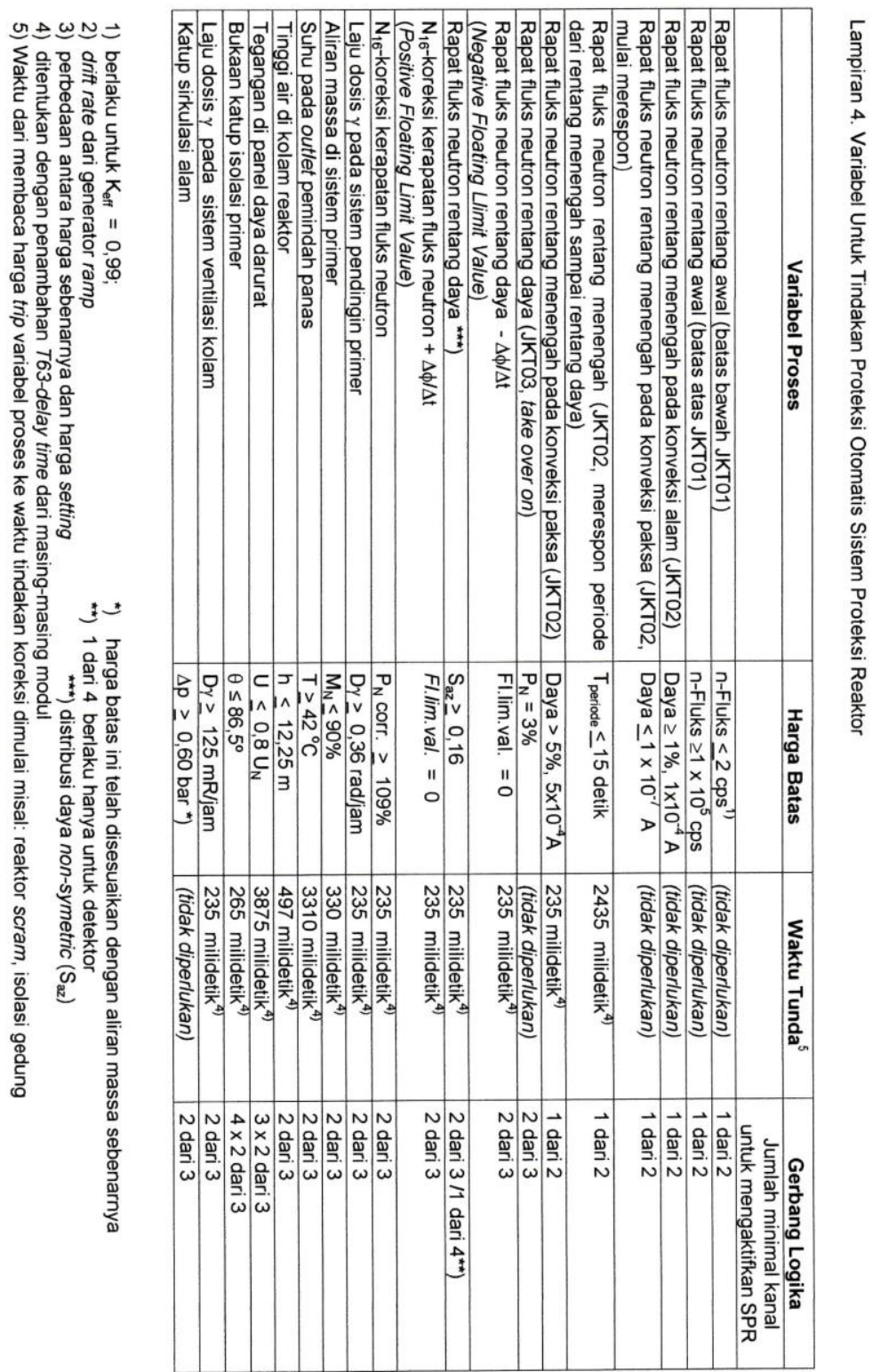

